${ }^{1}$ Revista Brasileira de Agricultura Irrigada v.6, no. 3, p. 198 - 206, 2012

ISSN 1982-7679 (On-line)

Fortaleza, CE, INOVAGRI - http://www.inovagri.org.br

DOI: $10.7127 /$ rbai.v6n300084

Protocolo 084.12 - 11/05/2012 Aprovado em 24/08/2012

\title{
DESEMPENHO DE CULTIVARES E LINHAGENS DE AMENDOIM IRRIGADO
}

\author{
Fabiano José de Campos Bastos ${ }^{1}$, Anísio Correa da Rocha ${ }^{2}$, Nelmício Furtado da Silva ${ }^{3}$, \\ Fernando Nobre Cunha ${ }^{3}$, Felipe Carreira da Silva ${ }^{3}$, Marconi Batista Teixeira ${ }^{4}$.
}

\section{RESUMO}

O experimento foi desenvolvido em condições de campo, na estação experimental do Instituto Federal Goiano - Campus Rio Verde, Estado de Goiás. Objetivou-se avaliar o desempenho de cultivares e linhagens de amendoim (Arachis hypogaea L) no período de inverno, sob sistema de irrigação, visando à utilização deste material como alternativa para a entressafra. Aplicou-se uma lâmina de $700 \mathrm{~mm}$, utilizando aspersores convencionais. As parcelas experimentais, foram constituídas de 5 linhas, espaçadas a $0,5 \mathrm{~m}$ com $4,0 \mathrm{~m}$ de comprimento $\left(10 \mathrm{~m}^{2}\right)$, com 12 plantas $/ \mathrm{m}^{2}$, com população de 240.000 plantas $/ \mathrm{ha}^{-1}$. Os tratamentos foram compostos por três cultivares $(\mathrm{T} 1=\mathrm{BR}-1, \mathrm{~T} 2=\mathrm{BRS}$ Havana, $\mathrm{T} 3=\mathrm{Tatu}) \mathrm{e}$ three linhagens $(\mathrm{T} 4=184$ AM, T5= 283 AM, T6= 298 AM), oriundas do Programa de Melhoramento de Amendoim da Embrapa, exceto a cultivar Tatu (IAC). O Delineamento experimental utilizado foi em blocos ao acaso, com 6 tratamentos e 4 repetições.Os dados experimentais foram submetidos à análise da variância, as médias comparadas entre si pelo teste Tukey a 5\% de probabilidade, utilizando-se SISVAR. O tratamento que mais se destacou quanto ao rendimento de grãos e produtividade foi o $283 \mathrm{AM}$.

Palavras chave: Arachis hypogaea L., melhoramento, irrigação.

\section{PERFORMANCE OF CULTIVARS AND STRAINS OF PEANUT IRRIGATED}

\section{ABSTRACT}

The experiment was conducted in field conditions, at the experimental station of the Instituto Federal Goiano - Campus Rio Verde - GO. The objective was to value the performance of cultivars and strains of peanut (Arachis hypogaea L) during winter, in irrigation system, aiming the utilization of this material as alternative to intercrop. Was applied a depth of $700 \mathrm{~mm}$, using conventional sprinklers. The experimental plots were composed of five lines, spaced at $0,5 \mathrm{~m}$ with $4,0 \mathrm{~m}$ of length $\left(10 \mathrm{~m}^{2}\right)$, with 12 plants $/ \mathrm{m}^{2}$, with a population of 240.000 plants $/ \mathrm{ha}^{-1}$. The treatments were composed of three cultivars $(\mathrm{BR}-1=$ T1, T2 = BRS Havana, T3 = Tatu $)$ and three strains $(\mathrm{T} 4=184$ AM, 283 AM =T5, T6 = 298

\footnotetext{
${ }^{1}$ Acadêmico de Agronomia, Instituto Federal de Educação, Ciência e Tecnologia - Campus Rio Verde. Rodovia Sul Goiana km 01, CEP 75901-970, Rio Verde, GO. E-mail: fabianojcbastos@ gmail.com.

${ }^{2}$ Engenheiro Agrônomo, Doutor em Agronomia, Professor, Instituto Federal de Educação, Ciência e Tecnologia - Campus Rio Verde. Rodovia Sul Goiana km 01, CEP 75901-970, Rio Verde, GO.

${ }^{3}$ Acadêmico de Agronomia, Instituto Federal de Educação, Ciência e Tecnologia - Campus Rio Verde. Rodovia Sul Goiana km 01, CEP 75901-970, Rio Verde, GO.

${ }^{4}$ Engenheiro Agrônomo, Doutor em Agronomia, Professor, Instituto Federal de Educação, Ciência e Tecnologia - Campus Rio Verde. Rodovia Sul Goiana km 01, CEP 75901-970, Rio Verde, GO.
} 


\section{DESEMPENHO DE CULTIVARES E LINHAGENS DE AMENDOIM IRRIGADO}

AM), originated from the Peanut Breeding Program of Embrapa, except the cultivar Tatu (IAC). The experimental design was randomized blocks, with 6 treatments and 4 replicates. The experimental data were submitted to analysis of variance, means were compared with each other by test Tukey at $5 \%$ of probability, using the SISVAR. The treatment that more contrasted on the yield of grains and productivity was the 283 AM.

Key words: Arachis hypogaea L., breeding, irrigation.

\section{INTRODUÇÃO}

\section{$\mathrm{O}$ amendoim (Arachis hypogaea} L.), oleaginosa pertencente à família Fabaceae, tem origem na América do Sul, na região compreendida entre as latitudes $10^{\circ}$ e $30^{\circ} \mathrm{S}$, entre o Amazonas e a Argentina. No Brasil, a cultura é explorada em larga escala no estado de São Paulo, que responde por cerca de $80 \%$ da produção.

Segundo Santos et al., (2006), na agricultura brasileira, o amendoim tem se destacado por ser de fácil manejo, ciclo curto, além das várias formas em que o produto é utilizado (consumo in natura, processados, óleos e combustível alternativo) o que incentiva a produção e expansão desta cultura.

$\mathrm{O}$ cultivo do amendoim visa principalmente à obtenção de sementes destinadas à extração de óleo e o consumo in natura, torrada ou empregada na fabricação de doces. Atualmente, estuda-se o amendoim como sendo uma planta com potencial para a produção do biodiesel, já que a semente possui alto teor de óleo, superando inclusive a soja (Gonçalves et al., 2004).

Apesar de ser uma cultura pouco produzida no Estado de Goiás especialmente na região Sudoeste, observase potencial para o uso de irrigação, por parte dos produtores e solos propícios para a exploração da cultura do amendoim, sendo assim uma alternativa para o período da entressafra. Além disso, a região apresenta um grande potencial na indústria alimentícia e falta de alternativas para culturas de inverno.

A produção nacional na safra 2011/2012 foi de 294,5 mil toneladas e no
Estado de Goiás foi de 6,4 mil toneladas.A área cultivada com amendoim no Brasil na safra de 2011/2012 foi de 96,5 mil ha, no Estado de Goiás a partir da safra 2004/2005 até a safra 2011/2012 cresceu de 500 ha para 2600 ha e as produtividades vem sendo elevadas, resultado da vinda de produtores altamente tecnificados, maior demanda e das boas condições da região para o cultivo do amendoim (Conab, 2011).

Em clima seco, sabe-se que a irrigação aumenta consideravelmente a produtividade do amendoim. Já em climas úmidos, pode ocorrer um pequeno aumneto ou nenhum incremento de produtividade quando se aplica a irrigação (Câmara et al., 1983).

Segundo Doorenbos \& Kassam (1994), a cultura do amendoim necessita de aplicação de 500 a $700 \mathrm{~mm}$ de água durante o seu ciclo de cultivo para expressar seu ótimo potencial produtivo.

A migração das espécies cultivadas tem sido um dos mais importantes fatores de desenvolvimento da agricultura mundial. A introdução de variedades melhoradas de outras regiões pode resultar na disponibilidade imediata de tipos superiores, à semelhança daqueles desenvolvidos em programas de melhoramento (Borem, 2005).

Variedades melhoradas de diversas espécies são levadas constantemente para outras regiões. Em regiões ou países com condições edafoclimáticas semelhantes, pode-se, muitas vezes, estabelecer intercâmbio de variedades de uma forma mutuamente proveitosa. É importante conhecer o desempenho das cultivares e linhagens disponíveis de amendoim no Sudoeste goiano visando tanto a 


\section{DESEMPENHO DE CULTIVARES E LINHAGENS DE AMENDOIM IRRIGADO}

recomendação de cultivares registradas de amendoim, cultivo na entressafra (adaptabilidade à irrigação), quanto o lançamento de novas cultivares para a região. Diante do exposto a pesquisa teve

\section{MATERIAL E MÉTODOS}

O estudo foi desenvolvido em condições de campo na estação experimental do Instituto Federal Goiano Campus Rio Verde, Estado de Goiás. "As coordenadas geográficas do local de instalação são $17^{\circ} 48^{\prime} 28^{\prime \prime} \mathrm{S}$ e $50^{\circ} 533^{\prime} 57^{\prime}$ ' O, com altitude média de 720 metros. O clima por objetivo avaliar o desempenho de cultivares e linhagens de amendoim no período de inverno, sob sistema de irrigação por aspersão no sudoeste do Estado de Goiás.

da região é classificado conforme Köppen, como Aw (tropical), com chuva nos meses de Outubro à Maio, e com seca nos meses de Junho à Setembro, ou seja, com chuva no verão e seca no inverno. A temperatura média anual varia de 20 a $35{ }^{\circ} \mathrm{C}$ e as precipitações variam de 1.500 a $1.800 \mathrm{~mm}$ anuais (Figura 1).

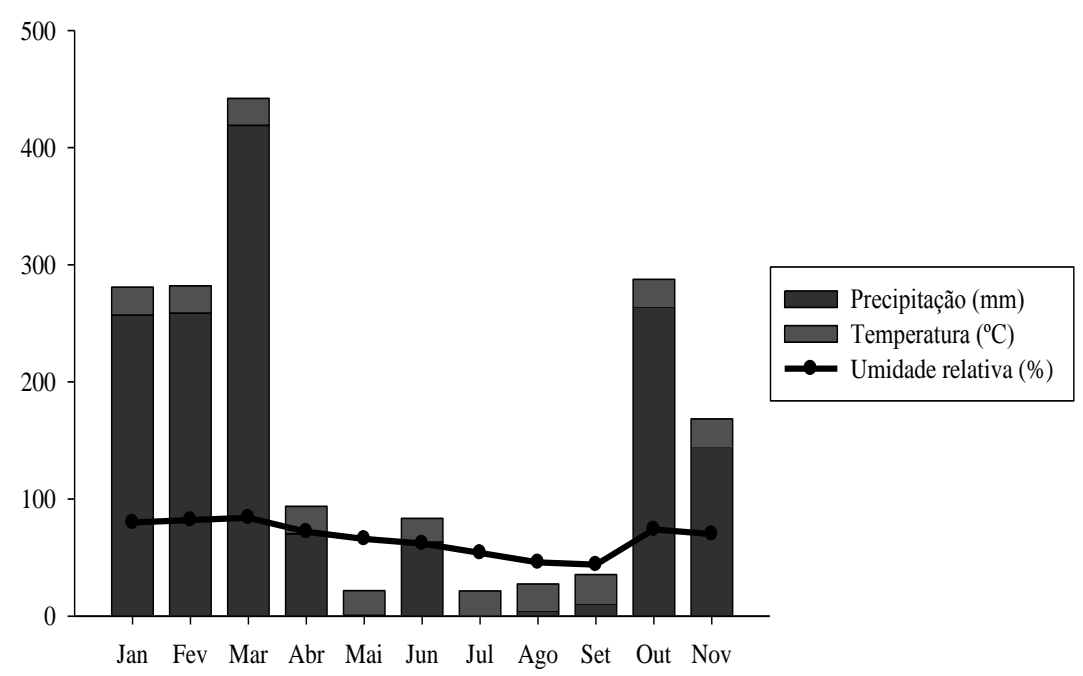

Figura 1. Dados pluviométricos da estação meteorológica da FESURV - Universidade de Rio Verde 2011, referentes a precipitação, temperatura e UR durante os meses de desenvolvimento da cultura do amendoim.

O relevo é suave ondulado $(8 \%$ de declividade) e o solo foi classificado como Latossolo Vermelho distroférrico (LVdf), de textura média (Embrapa, 2006). As principais características químicas e físicas deste solo são apresentadas na Tabela 1 .

A semeadura foi realizada no dia 06 de julho de 2011. O espaçamento utilizado foi de $0,50 \mathrm{~m}$ entre linhas e densidade de 12 sementes $/ \mathrm{m}$ linear, densidade populacional de 240.000 plantas $/ h^{-1}$. A adubação foi realizada de acordo com a recomendação da análise de solo Tabela 1, segundo as recomendações da Embrapa (2004). 
DESEMPENHO DE CULTIVARES E LINHAGENS DE AMENDOIM IRRIGADO

Tabela 1. Características químicas e físicas do solo da área experimental, Latossolo Vermelho Distroférrico, na camada de $0-20 \mathrm{~cm}$ de profundidade antes da implantação do pesquisa.

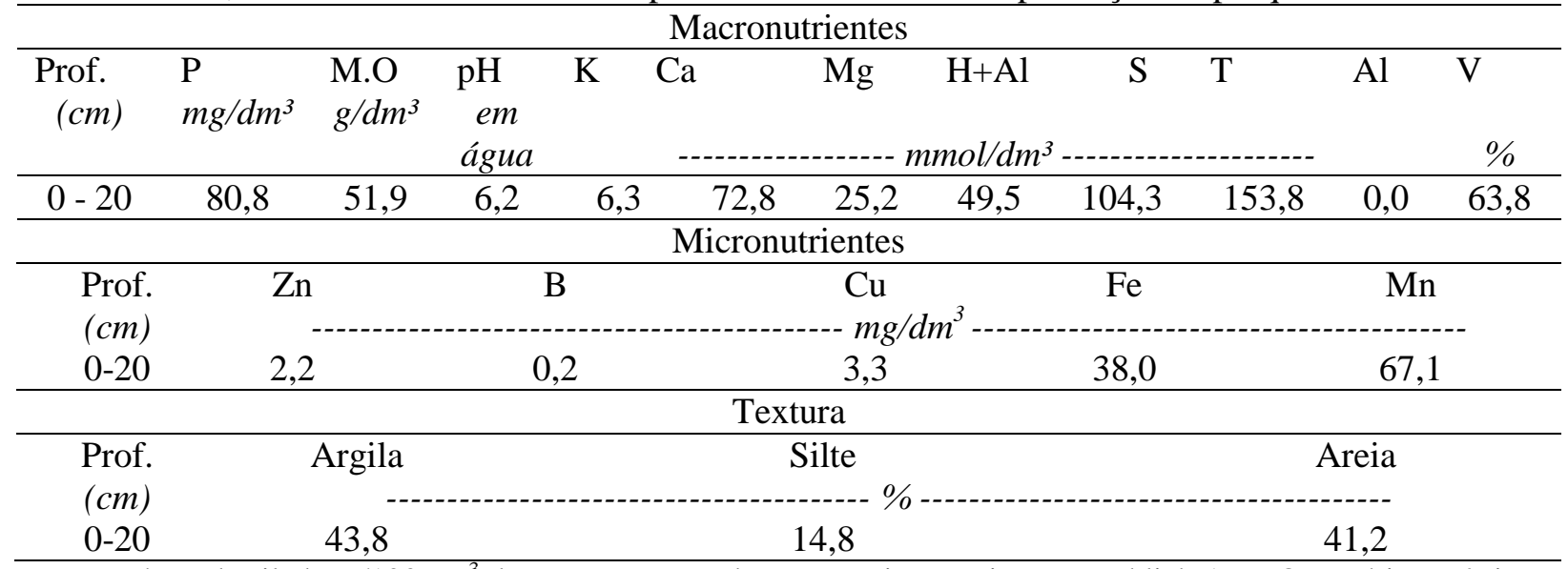

$\mathrm{pH}$ em água destilada, $\mathrm{g} / 100 \mathrm{~cm}^{3}$ de terra. Extrator de $\mathrm{P}, \mathrm{K}$ e micronutrientes, Mehlich-1. M.O matéria orgânica, T capacidade de troca de cátions, $\mathrm{S}+\mathrm{H}+\mathrm{Al}$. V porcentagem de saturação de bases, V=100 S/T.

$\mathrm{O}$ delineamento experimental foi $\mathrm{o}$ de blocos ao acaso com 6 tratamentos e 4 repetições. Cada unidade experimental foi composta de parcelas com $4,0 \mathrm{~m}$ de comprimento por $2,5 \mathrm{~m}$ de largura $(10,00$ $\mathrm{m}^{2}$ ), com cinco linhas espaçadas a $0,50 \mathrm{~m}$. Foram avaliadas as três linhas centrais, com área útil de $\left(6,0 \mathrm{~m}^{2}\right)$.

Os tratamentos foram compostos por cultivares (BR-1, BRS Havana, Tatu) e linhagens (184 AM, 283 AM, 298 AM), oriundas do Programa de Melhoramento de Amendoim da Embrapa, exceto a cultivar Tatu (IAC), todos os tratamentos foram submetidos a regimes de $100 \%$ de irrigação, ou seja, foi fornecida a quantidade de água necessária para o pleno desenvolvimento da cultura, lâmina de 700 $\mathrm{mm}$. A irrigação foi manejada de forma a manter o solo sempre dentro da capacidade de campo. Utilizou-se um sistema de irrigação por aspersão convencional fixo, composto por aspersores Duro Plastic, modelo D148 (setorial) com diâmetro de bocal de $2,8 \mathrm{~mm}$, vazão de $0,55 \mathrm{~m}^{3} \mathrm{~h}^{-1}$, raio de alcance de $11,8 \mathrm{~m}$ e altura de trabalho igual a $1,5 \mathrm{~m}$.

O sistema foi composto por dois ramais com tubulação de $20 \mathrm{~mm}$ interligados paralelamente à linha principal do sistema $(50 \mathrm{~mm})$. A subida do aspersor foi composta por mangueira de polietileno $(20 \mathrm{~mm})$ com altura de $1,5 \mathrm{~m}$ em relação à superfície do solo.
O sistema de bombeamento foi composto por: bomba Thebe, modelo $\mathrm{R} 20$ mancal, série 9710 015; motor Kohlbach $10 \mathrm{cv}$ trifásico, voltagem $220 / 380 \mathrm{~V}$ e amperagem 26/15 A.

Antes da instalação do sistema realizou-se um teste de uniformidade de aplicação de água em função de se corrigir qualquer irregularidade no sistema e aplicar com maior exatidão a mesma lâmina de água para todas as cultivares e linhagens de amendoim utilizadas. Para se ter uma menor interferência dos fatores climáticos a irrigação foi realizada sempre pela manhã e no final da tarde.

O controle de plantas invasoras foi realizado manualmente com o uso de enxadas, sendo necessárias três capinas para o bom desenvolvimento da cultura. Realizou-se uma aplicação do inseticida do grupo piretróide e uma aplicação de fungicida do grupo dos triazóis.

A colheita foi realizada 133 dias após a semeadura (DAS), manualmente. Depois de colhidas as parcelas foram colocadas para secar até atingirem $8 \%$ de umidade, posteriormente foram pesadas para determinação da produtividade $\mathrm{e}$ avaliação das demais características.

As variáveis analisadas foram: número de vagens por planta, número de grãos por vagem, peso médio de grãos, produtividade e rendimento em grãos. $\mathrm{O}$ peso médio de grãos foi determinado 


\section{DESEMPENHO DE CULTIVARES E LINHAGENS DE AMENDOIM IRRIGADO}

utilizando-se uma amostra de 100 grãos por parcela.

A produtividade foi estimada em função do rendimento de vagens na área útil de cada parcela. $\mathrm{O}$ número de vagens por planta foi obtido numa amostra de 10 plantas por parcela. O rendimento em grãos foi estimado pelo quociente entre o

\section{RESULTADOS E DISCUSSÃO}

Nas condições propostas, em comparação as variáveis produtivas avaliadas para as cultivares e linhagens de amendoim, na variável número de vagens por planta (tabela 2), a linhagem 283 AM se diferiu significativamente segundo teste de Tukey a $5 \%$ de probabilidade da linhagem 184 AM, das cultivares Tatu e BRS Havana, não se diferindo da cultivar peso de sementes obtido em 100 vagens e o peso de 100 vagens.

Os dados experimentais foram submetidos à análise da variância sendo que as médias dos tratamentos foram comparadas entre si pelo teste Tukey a 5\% de probabilidade. Utilizando-se SISVAR para processamento dos dados.

BR1 e da linhagem 298 AM. Para o número de grãos por vagem e número de grãos de cem vagens, a linhagem 298 AM e a cultivar Tatu se diferiu das demais cultivares e linhagens, exceto da cultivar BRS Havana, no geral, a linhagem 298 $\mathrm{AM}$ foi superior às demais. Isso pode ser explicado pelo fato de algumas linhagens possuírem maior capacidade de adaptação às condições edafoclimáticas da região.

Tabela 2. Variáveis produtivas avaliadas nas plantas de amendoim

\begin{tabular}{cccc}
\hline Tratamentos & N vagens planta & N grãos vagem & N grãos 100 vagens \\
\hline BR1 & $31,62 \mathrm{ab}$ & $2,77 \mathrm{c}$ & $277,00 \mathrm{c}$ \\
BRS HAVANA & $26,00 \mathrm{a}$ & $2,86 \mathrm{~cd}$ & $285,75 \mathrm{~cd}$ \\
TATU & $26,70 \mathrm{a}$ & $2,62 \mathrm{~b}$ & $262,00 \mathrm{~b}$ \\
$184 \mathrm{AM}$ & $27,30 \mathrm{a}$ & $1,87 \mathrm{a}$ & $186,75 \mathrm{a}$ \\
$283 \mathrm{AM}$ & $39,80 \mathrm{~b}$ & $1,97 \mathrm{a}$ & $197,00 \mathrm{a}$ \\
$298 \mathrm{AM}$ & $29,45 \mathrm{ab}$ & $2,91 \mathrm{~d}$ & $291,25 \mathrm{~d}$ \\
\hline Erro & 2,30542 & 0,03073 & 3,07374 \\
DMS & 10,36445 & 0,13818 & 13,81861 \\
CV $(\%)$ & 15,30 & 2,46 & 2,46 \\
\hline
\end{tabular}

*Médias seguidas de mesma letra nas colunas não diferem significativamente entre si segundo teste Tukey $(\mathrm{P}<0,05)$; (número de vargens por planta - $\mathrm{N}$ vagem planta; número grãos por vargem - $\mathrm{N}$ grãos vagem; número de grãos de 100 vagens - N grãos 100 vagens).

Silva et al. (1993) trabalhando com diferentes lâminas e intervalos de irrigação em amendoim, verificou que a percentagem de vagens chochas, embora com valores baixos, foi influenciada tanto pela lâmina quanto pelo intervalo de irrigação, variando de 3,5 a $8,5 \%$ na lâmina de $300 \mathrm{~mm}$, de 3,75 a $4,75 \%$ na lâmina de $500 \mathrm{~mm}$ e de 1,75 a $4,75 \%$ na lâmina de $700 \mathrm{~mm}$. Esses valores são indicadores de que o suprimento de cálcio mais magnésio na zona de desenvolvimento das vagens era satisfatório, visto que a deficiência de cálcio para a planta do amendoim é o principal fator responsável pela formação de vagens chochas, conforme atestam diversos autores citados por Silva et al. (1993). Dessa forma, consequentemente haver um maior investimento em produção de grãos, conforme disposto na Tabela 2.

Para peso de grãos de cem vagens (tabela 3), a média de maior destaque foi da cultivar BRS Havana, se diferindo da cultivar Tatu e das linhagens 184 AM e 283 AM. Para o peso de grãos de cem vagens não houve diferença significativa entre os tratamentos. A linhagem 184 AM se destacou dos demais tratamentos, quando avaliado o peso de cem grãos por 


\section{DESEMPENHO DE CULTIVARES E LINHAGENS DE AMENDOIM IRRIGADO}

parcela, conforme disposto na Tabela 3. Em amendoim, a ocorrência de déficit hídrico nas fases de crescimento e desenvolvimento dos ginóforos e das vagens, acarreta decréscimo na produção, pela redução do número de vagens antes mesmo que pelo peso das vagens, e sementes (Boote et al., 1976); entretanto, alguns pesquisadores (Wright et al., 1991) afirmam que déficit hídrico durante o enchimento das vagens geralmente reduz o peso das sementes e das vagens.

Tabela 3. Variáveis produtivas avaliadas nas plantas de amendoim

\begin{tabular}{|c|c|c|c|}
\hline Tratamentos & P 100 vagens & P grãos 100 vagens & P 100 grãos parcela \\
\hline \multicolumn{4}{|c|}{ 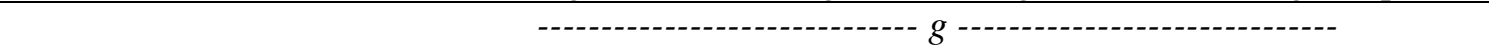 } \\
\hline BR1 & $191,01 \mathrm{bc}$ & $147,52 \mathrm{~b}$ & $53,73 \mathrm{ab}$ \\
\hline BRS HAVANA & $196,19 \mathrm{c}$ & $152,54 \mathrm{~b}$ & $53,32 \mathrm{a}$ \\
\hline TATU & $172,31 \mathrm{ab}$ & $133,08 \mathrm{ab}$ & $50,11 \mathrm{a}$ \\
\hline $184 \mathrm{AM}$ & $168,67 \mathrm{ab}$ & $127,70 \mathrm{a}$ & $66,83 \mathrm{c}$ \\
\hline 283 AM & $152,93 \mathrm{a}$ & $121,35 \mathrm{a}$ & $59,62 \mathrm{~b}$ \\
\hline $298 \mathrm{AM}$ & $180,84 \mathrm{bc}$ & $140,72 \mathrm{ab}$ & $48.77 \mathrm{a}$ \\
\hline Erro & 5,13787 & 4,35982 & 1,37368 \\
\hline DMS & 23,09829 & 19,60040 & 6,17567 \\
\hline $\mathrm{CV}(\%)$ & 5,81 & 6,36 & 4,96 \\
\hline
\end{tabular}

*Médias seguidas de mesma letra nas colunas não diferem significativamente entre si segundo teste Tukey $(\mathrm{P}<0,05)$; (peso de 100 vagens - P 100 vagens; peso de grãos de 100 vagens - P grãos 100 vagens; peso de 100 grãos por parcela - P 100 grãos por parcela).

As médias de produtividade $\mathrm{e}$ rendimento de grãos obtidas no experimento, encontram-se na Tabela 4. Observa-se que a maior produtividade de vagens foi conseguida com a linhagem 283 $\mathrm{AM}$, com 5. $937 \mathrm{~kg} \mathrm{ha}^{-1}$, se diferindo apenas das linhagens 298 AM, 184 AM e da cultivar BRS Havana (5.320,83; 5.291,67; 5.083,33 kg.ha ${ }^{-1}$ ). A média do rendimento de grãos da linhagem 298 AM foi $79,26 \%$, considerado excelente para os critérios de seleção estabelecidos no programa de melhoramento de amendoim da Embrapa. No entanto só se difere estatisticamente da linhagem 184 AM. Conforme disposto para melhor visualização na Figura 2.

Tabela 4. Variáveis produtivas das cultivares e linhagens.

\begin{tabular}{ccc}
\hline Tratamentos & Rendimento & Produtividade \\
\hline & $\%$ & $k g h a^{-1}$ \\
BR1 & $77,24 \mathrm{ab}$ & $5.833,33 \mathrm{~b}$ \\
BRS HAVANA & $77,73 \mathrm{ab}$ & $5.083,33 \mathrm{a}$ \\
TATU & $77,24 \mathrm{ab}$ & $5.875,00 \mathrm{~b}$ \\
$184 \mathrm{AM}$ & $75,73 \mathrm{a}$ & $5.291,67 \mathrm{a}$ \\
$283 \mathrm{AM}$ & $79,26 \mathrm{~b}$ & $5.937,50 \mathrm{~b}$ \\
298 AM & $77,79 \mathrm{ab}$ & $5.320,83 \mathrm{a}$ \\
\hline Erro & 0,00711 & 81,16389 \\
DMS & 0,03200 & 364,88776 \\
CV $(\%)$ & 1,84 & 2,92 \\
\hline
\end{tabular}

*Médias seguidas de mesma letra nas colunas não diferem significativamente entre si segundo teste Tukey $(\mathrm{P}<0,05)$; (Rendimento - rendimento de grãos = Peso de cem vagens/peso de grãos de cem vagens x 100; 


\section{DESEMPENHO DE CULTIVARES E LINHAGENS DE AMENDOIM IRRIGADO}

Produtividade - produtividade em casca, os resultados obtidos foram transformados para $\mathrm{kg} \mathrm{ha}^{-1}$, corrigindo-se a umidade para $8 \%$ em base úmida).

Dessa forma, podemos observar que todos as cultivares de amendoim tiveram um bom desempenho mediante o efeito da irrigação. Pois segundo Bastos et al. (2011) em um experimento na mesma localidade em condições de sequeiro no período de verão, trabalhando com estas mesmas cultivares e linhagens, observou a seguinte ordem crescente de produtividade: 283 AM > 298 AM > 184 AM > BR1 > Tatu > BRS Havana, com produtividades observadas e respectivas a 1574,50; 1637,$00 ; 1994,00 ; 2021,50 ; 2154,00$ e $2377,50 \mathrm{~kg} \mathrm{ha}^{-1}$. Estes resultados estão de acordo com Peixoto et al. (2008) onde afirma que o potencial de produção do amendoim é determinado geneticamente e quanto deste potencial vai ser exteriorizado depende de fatores limitantes que estarão atuando em algum momento durante o ciclo da cultura.

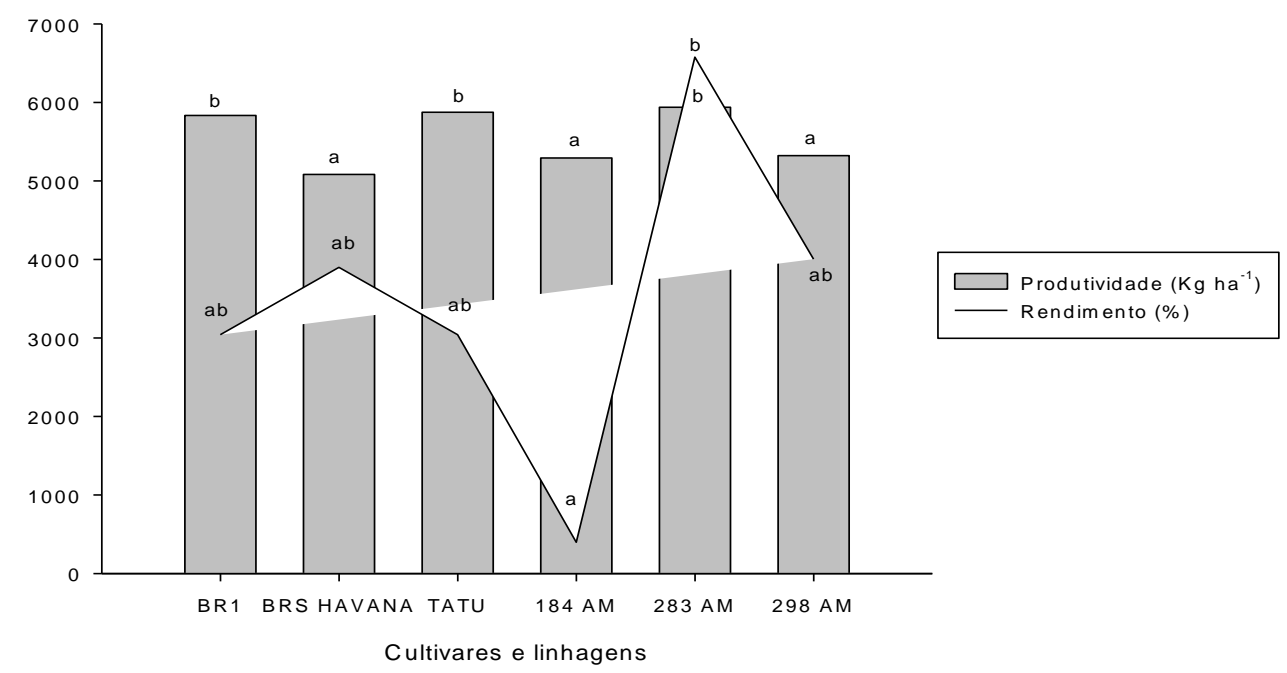

Figura 2. Rendimento e produtividade de grãos das cultivares e linhagens de amendoim.

A irrigação esta entre os principais fatores de aumento de produtividade do amendoim, as condições de déficit hídrico pode levar a uma queda de produtividade uma vez que estas plantas possuem boa capacidade de resposta a irrigação. Nageswara Rao et al. (1988) aplicando lâminas de água de $725 \mathrm{~mm}, 630 \mathrm{~mm}, 580$ $\mathrm{mm}$ e $550 \mathrm{~mm}$, obtiveram produtividades de amendoim em casca de $4615 \mathrm{~kg} . \mathrm{ha}^{-1}$, 5480 kg.ha ${ }^{-1}, 5040$ kg.ha ${ }^{-1}$ e 3687 kg.ha ${ }^{-1}$ , respectivamente, evidenciando que água, em demasia quanto em deficiência, reflete negativamente na produção. Também, Távora \& Melo (1991) verificaram que a deficiência hídrica determinou redução média na produção de vagens de amendoim, da ordem de $62 \%$ em relação ao tratamento sem deficiência hídrica.

\section{CONCLUSÕES}

A linhagem 298 AM foi superior as demais para número de grãos por vagem e número de grãos em 100 vagens. Já para peso de 100 grãos por parcela a linhagem 184 AM foi melhor. O tratamento de maior destaque quanto à produtividade $\mathrm{e}$ rendimento de grãos foi a linhagem 283 AM.

Os genótipos apresentaram boa resposta à irrigação, com expressivo acréscimo de produtividade. De maneira geral, observou a seguinte ordem crescente de produtividade: BRS Havana > 184 AM > 298 AM > BR1 > Tatu > 283 AM.

Recomenda - se o cultivo no estado de Goiás das cultivares da Embrapa (BR-1, 


\section{DESEMPENHO DE CULTIVARES E LINHAGENS DE AMENDOIM IRRIGADO}

BRS Havana) e linhagens (184 AM, 283 AM, 298 AM) e a linhagem do IAC (Tatu).

\section{AGRADECIMENTOS}

Os autores agradecem ao Conselho Nacional de Desenvolvimento

\section{REFERÊNCIAS BIBLIOGRÁFICAS}

BASTOS, F. J. C.; ROCHA, A. C.; SUASSUNA, T. M. F. Desempenho de cultivares e linhagens de amendoim de porte ereto e rasteiro no sudoeste de Goiás. In: CICURV - Congresso de Iniciação Científica da Universidade de Rio Verde, 5., 2011, Rio Verde Goiás. Anais eletrônicos... Rio Verde: Fesurv, 2011. Disponível em: http://www.eventosfesurv.com.br/fckfiles/f iles/Anais_V\%20Cicurv.pdf. Acesso em: 15 Fev. 2011.

BOOTE, K.J.; VARNELL, R.J.; DUNCAN, W.G. Relationships of size, osmotic concentration, and sugar concentration of peanut pods to soil water. Proceedings Soil and Crop Science Society of Florida, v.35, p.47-50, 1976.

BOREM, A, MIRANDA, G.V. Melhoramento de plantas. 4ed. Viçosa:UFV. 525p, 2005.

CÂMARA， G.M.S.; GODOY， O.P.; FILHO, J.M.; FONSECA, H. Técnica cultural. In: Produção, pré-processamento e transformação agroindustrial. Piracicaba: FEALQ, 1983. p.1-38. (Série Extensão Agrícola, 3).

COMPANHIA NACIONAL DE ABASTECIMENTO - CONAB. Safras. Levantamento safras anteriores por produto: Amendoim. Disponível em: http://www.conab.gov.br/conabweb/downl oad/safra/AmendoimTotalSerieHist.xls acesso em 20 de Julho de 2011.

DOORENBOS, J.; KASSAM, A. H. Efeito da água no rendimento das
Científico e Tecnológico (CNPq) e ao Instituto Federal Goiano Campus Rio Verde, pelo espaço cedido e pelo apoio financeiro para desenvolvimento do trabalho.

culturas. Estudos de FAO: Irrigação e Drenagem, 33, Campina Grande: UFPB, 306p, 1994.

EMPRESA BRASILEIRA DE PESQUISA AGROPECUÁRIA - EMBRAPA. Cerrado. Brasília, DF; Empresa Brasileira de Pesquisa Agropecuária: Embrapa Informações Tecnológicas, 2004. 416p.

EMPRESA BRASILEIRA DE PESQUISA AGROPECUÁRIA - EMBRAPA. Centro Nacional de Pesquisa de Solos. Sistema brasileiro de classificação de solos. 2.ed. Rio de Janeiro, Embrapa Solos, 2006. 306p.

GONÇAVES, J.A.; PEIXOTO, C.P.; LEDO, C.A.S. Componentes de produção de amendoim em diferentes arranjos espaciais no Recôncavo Baiano. Revista Brasileira de Oleaginosas e Fibrosas, Campina Grande, v.8, n.2/3, p.801-812, maio/dez. 2004.

NAGESWARA RAO, R.C.; WILLIAMS, J.H.; SIVAKUMAR, M.V.K. Effect of water deficit at different growth phases of peanut. Response to drought during preflowering phase. Agronomy Journal, v.80, p.431-438, 1988.

PEIXOTO, C. P.; GONÇALVES, J. A.; PEIXOTO, M. F. S. P.; CARMO, D. O. Características agronômicas e produtividade de amendoim em diferentes espaçamentos e épocas de

semeadura no recôncavo baiano. Bragantia, Campinas, v.67, n.3, p.673-684, 2008. 
DESEMPENHO DE CULTIVARES E LINHAGENS DE AMENDOIM IRRIGADO

SANTOS, R. S.; FREIRE, R. M. M.; SUASSUNA, T. M. F. BRS Havana: nova cultivar de amendoim de pele clara. Brasília: Pesquisa Agropecuária Brasileira, v. 41, n. 8. 2006.

SILVA, L.C.; MOREIRA, J. de A.N.; TAVARES SOBRINHO, J.; BELTRÃO, N.E. de M. Recomendações técnicas para o cultivo do amendoim no Nordeste Brasileiro. Campina Grande: EMBRAPACNPA, 1993. 26p. (EMBRAPA-CNPA. Circular Técnica, 16).
TÁVORA, F. J. A. F.; MELO, F. I. O. Resposta de cultivares de amendoim a ciclos de deficiência hídrica: crescimento vegetativo, reprodutivo e relações hídricas. Ciência Agronômica, Fortaleza, v.22, n.1/2, p.47-60, 1991.

WRIGHT, G.C.; HUBICK, K.T.; FARQUHAR, G.D. Physiological analysis of peanut cultivar response to timing and duration of drought stress. Australian Journal for Agricultural Research, v.42, p.453-470, 1991. 